\title{
Determination of Phytosterols in vegetable oils by GC-MS method
}

\author{
Dang Thu Hien ${ }^{*}$ Mai Thi Ngoc Anh, Nguyen Thi Hong Ngoc \\ National Institute for Food Control, Hanoi, Vietnam
}

(Received: 15/09/2020; Accepted: 08/12/2020)

\section{Abstract}

In this study, a method for determination of six phytosterols by gas chromatography-mass spectrometry with derivatization in vegetable oils was validated. The samples were hydrolyzed in an alkaline media at $70^{\circ} \mathrm{C}$ for $60 \mathrm{~min}$. Then, the samples were performed liquid-liquid extraction with toluene. The phytosterols are derivatized to trimethylsilyl ethers and then analyzed by gas chromatography-mass spectrometry. The limit of detection and limit of quantification was 5 and $15 \mathrm{mg} / \mathrm{kg}$, respectively. Recoveries of six phytosterols were between $93.5 \%$ and $101 \%$.

Keywords: GC-MS, phytosterols, vegetable oils.

\section{INTRODUCTION}

Phytosterols are plant compounds that have similar chemical structures and biological functions as cholesterol. The most common phytosterols are sitosterol, campesterol, stigmasterol. Phytosterols have properties and biological effects, such as hypocholesterolemic, anti-inflammatory, anti-oxidative, and anti-tumor. The daily doses are 2-3 g of phytosterols to reduce both the total cholesterol and low-density lipoprotein cholesterol levels in the blood by $10 \%$ [6]. They are widely used in pharmaceuticals, nutritional supplements, and cosmetics [9].

In recent years, a few analytical methods have been developed for the determination of phytosterols for vegetable oils, nuts, foods. A method for the determination of cholesterol and four phytosterols in foods without derivatization by gas chromatography-tandem mass spectrometry was developed by Yan-Zong Chen et al. Limit of quantification was $2 \mathrm{mg} / \mathrm{kg}$. The recoveries of cholesterol and four phytosterols from general food were between 91 and 100\% [5].

Maria et al. developed the method for the determination of sterols in vegetable oils by ultraperformance liquid chromatography with atmospheric pressure chemical ionization mass spectrometry detection. The limits of detection of six sterols were from 0.03 to $0.07 \mu \mathrm{g} / \mathrm{mL}$. The content of 14 sterols in eight vegetable oils such as avocado oil, corn oil, extra virgin olive, grapeseed oil, hazelnut oil, peanut oil, soybean oil, and sunflower oil was established. The content of beta-sitosterol was the main sterols in all cases [1].

Our study aimed to validate a simple and accurate method for the determinations of six phytosterols including campesterol, beta-sitosterol, stigmasterol, $\Delta 7$-stigmasterol, $\Delta 5$-avenasterol, $\Delta 7$-avenasterol in some vegetable oils and investigated the phytosterols contents and composition of phytosterols of different kinds of vegetable oils. 


\section{MATERIALS AND METHODS}

\subsection{Chemicals and reagents}

Campesterol, beta-sitosterol, stigmasterol, $\Delta 5$-avenasterol, $\Delta 7$-avenasterol, $\Delta 7$-stigmasterol were obtained from Toronto (Canada). $5 a$-Cholestane used as an internal standard was purchased from Sigma-Aldrich. Toluene, dimethylformamide, hexamethyldisilane, potassium hydroxide, trimethylchlorosilane, sodium sulfate, acetone ethanol, n-heptane were obtained from Merck (Germany).

\subsection{Instruments}

A Trace 1310 Thermo GC equipped with an ISQ 7000 Thermo mass detector was used for the identification of phytosterols from vegetable oils. The analytes were separated using a TG$5 \mathrm{MS}$ Thermo column $(30 \mathrm{~m} \times 0.25 \mathrm{~mm}$ ID $\times 0.25 \mu \mathrm{m})$. The oven temperature program was set as follows: the initial temperature was $50^{\circ} \mathrm{C}$, held for $1 \mathrm{~min}$, and then the temperature ramped at $40^{\circ} \mathrm{C} / \mathrm{min}$ to $280^{\circ} \mathrm{C}$ and was held for $20 \mathrm{~min}$. The injection volume was $1 \mu \mathrm{L}$ in splitless mode. Helium was used as the carrier gas at a flow rate of $1 \mathrm{~mL} / \mathrm{min}$. The temperatures of the injector, transfer line, and ion source were set to 260,280 , and $250^{\circ} \mathrm{C}$, respectively. The mass scan range was $50-600 \mathrm{~m} / \mathrm{z}$. No mass spectrum was collected during the solvent delay for the first $6 \mathrm{~min}$ of each run. The scan was performed by selected ion monitoring mode (SIM).

Other equipment included magnetic stirrer-hot plate with variable speed and heat controls, rotary evaporator with glass condenser flask between concentration flask and metal shaft. Glasswares used included 250-mL Erlenmeyer flasks, 500-mL separatory funnel, volumetric flasks, glass funnels, and graduated cylinders.

\subsection{Sample preparation}

Some vegetable oils were collected from the markets such as soybean oil, rapeseed oil, sunflower oil, rice bran oil, palm oil. All oil samples were store in darkness at $4^{\circ} \mathrm{C}$ for further analysis.

The sample preparation referred to AOAC Official methods 2007.03 [4] with some modifications.

Saponification: Each sample was weighed around $2.00 \pm 0.1 \mathrm{~g}$ into a $250 \mathrm{~mL}$ Erlenmeyer flask, and added $50 \mathrm{~mL}$ of $20 \% \mathrm{KOH}$ in ethanol. The mixture was placed in an oven at $70^{\circ} \mathrm{C}$ for $60 \mathrm{~min}$, the mixture was gently shaken during the hydrolysis process. After that, the solution was left to cool down at room temperature.

Extraction: The saponified sample solution was transferred into a $500 \mathrm{~mL}$ separatory funnel and extracted twice by $60 \mathrm{~mL}$ toluene. The toluene fractions were combined and washed twice by $100 \mathrm{~mL} 5 \% \mathrm{NaCl}$ in water. The remaining toluene layer was poured into a glass funnel containing a filter paper and $20 \mathrm{~g}$ anhydrous $\mathrm{Na}_{2} \mathrm{SO}_{4}$ into a $125 \mathrm{~mL}$ Erlenmeyer flask. The whole solution was transferred into a $100 \mathrm{~mL}$ round-bottomed flask and evaporate the contents to dry. The residue was resuspended by $10.0 \mathrm{~mL}$ dimethylformamide.

Derivatization: one milliliter of working standard or sample solution was placed in a 15 $\mathrm{mL}$ centrifuge tube. Then, $0.2 \mathrm{~mL}$ hexamethyldisilane and $0.1 \mathrm{~mL}$ trimethylchlorosilane were added into the tube and shaken vigorously on a vortex mixer for 30 secondes. The solution was left for $15 \mathrm{~min}$ at room temperature before adding $1.0 \mathrm{~mL}$ of $5 a$-cholestane IS solution and $10 \mathrm{~mL}$ 
water. The mixture was shaken well and centrifuged for $2 \mathrm{~min}$. Finally, the $\mathrm{n}$-heptane layer was transferred into a vial and analyzed by GC-MS.

\section{RESULTS AND DISCUSSION}

\subsection{Method validation}

\subsubsection{Specificity}

Blank samples, spiked samples, and standard solutions were analyzed. Six phytosterols were detected on the GC-MS system. The concentration of phytosterols was measured by using the single ion monitoring mode (SIM). Each compound was identified by two ions that were shown in Table 1 . Beta-sitosterol, $\Delta 5$-avenasterol, and $\Delta 7$-avenasterol were eluted at the nearby time. However, it does not affect the detection as the identification ions were different.

Table 1. Identification ions and retention time of phytosterols

\begin{tabular}{lcc}
\hline Compounds & Ions $(\boldsymbol{m} / \mathbf{z})$ & Retention time (min) \\
\hline Campesterol & $343.47,382.51$ & 16.24 \\
Stigmasterol & $255.34,394.53$ & 16.75 \\
Beta sitosterol & $357.48,396.53$ & 17.78 \\
$\Delta 5$-avenasterol & $296.37,386.47$ & 17.95 \\
$\Delta 7$-avenasterol & $255.32,343.39$ & 17.92 \\
$\Delta 7$-stigmaterol & $351.47,377.48$ & 17.53 \\
\hline
\end{tabular}

Figure 1 shown the chromatogram of a blank sample, a spiked sample, and a standard solution of beta-sitosterol. One peak was detected at the retention time of around $17.78 \mathrm{~min}$ in the chromatograms of the spiked sample and the standard solution. The chromatogram of the blank sample did not show any peak at that time. Overall, the specificity of the method meets the requirements of AOAC International.

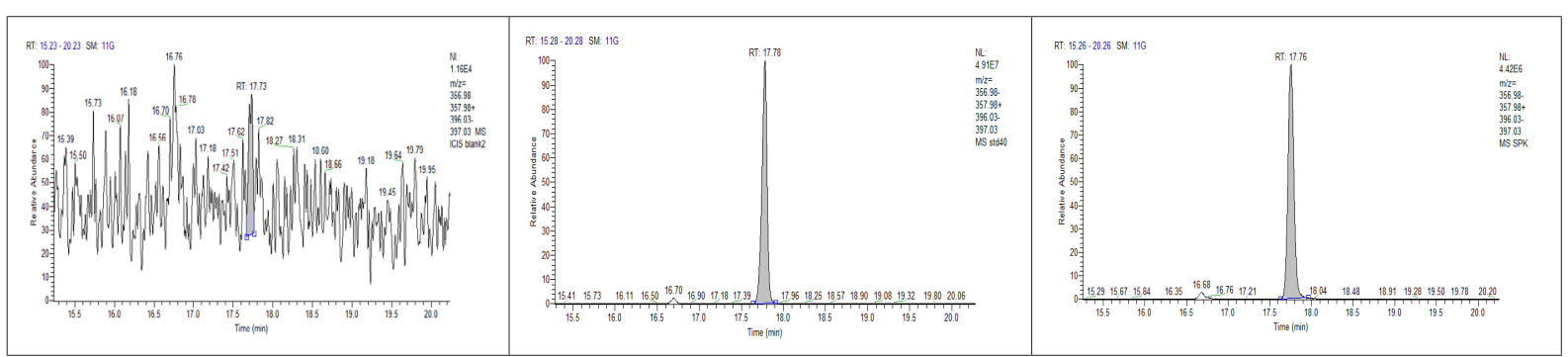

Figure 1. Chromatogram of a blank sample, a spiked sample, and a standard solution of beta-sitosterol

\subsubsection{The linearity, limit of detection, limit of quantitation}

The linearity of the chromatographic response was tested using five concentrations in the range of $1-20 \mathrm{mg} / \mathrm{L}$. The TIC and SIM of six phytosterols at $20 \mathrm{mg} / \mathrm{L}$ are shown in Figure 2. The linear regression $\left(R^{2}\right)$ for all the calibration curves used in this study was $\geq 0.995$ (Table 2). 


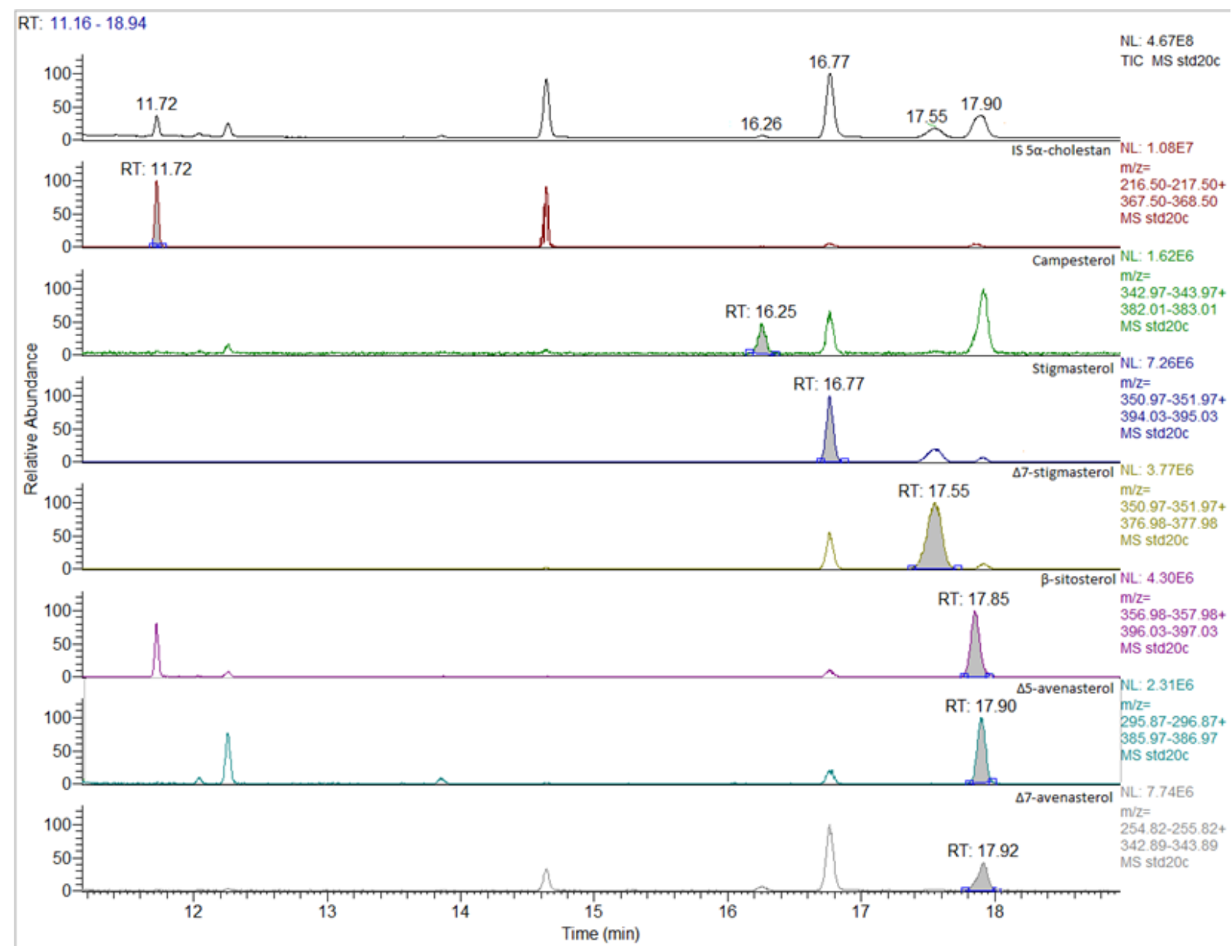

Figure 2. Chromatogram of phytosterols standard solution $20 \mathrm{mg} / \mathrm{L}$

Limits of quantitation were evaluated by spiking the lowest concentration of six phytosterols in the blank samples. All signal to noise ratios of the analyte's peaks after sample treatment at a low spiked concentration have to be less than 10 for all double tests. LOQs were $15 \mathrm{mg} / \mathrm{kg}$ for six phytosterols. LODs were proposed $5 \mathrm{mg} / \mathrm{kg}$ for six phytosterols.

Table 2. Linear correlation coefficients of the phytosterols content

\begin{tabular}{ccc}
\hline Compounds & Linear equation & $\begin{array}{c}\text { Correlation coefficient } \\
\left(\boldsymbol{R}^{2}\right)\end{array}$ \\
\hline Campesterol & $\mathrm{y}=0.2342 \mathrm{x}-0.1704$ & 0.999 \\
Stigmasterol & $\mathrm{y}=0.0767 \mathrm{x}-0.0432$ & 0.999 \\
Beta-sitosterol & $\mathrm{y}=0.041 \mathrm{x}-0.0352$ & 0.998 \\
$\Delta$ 5-avenasterol & $\mathrm{y}=0.0218 \mathrm{x}-0.0201$ & 0.996 \\
$\Delta 7$-avenasterol & $\mathrm{y}=0.0367 \mathrm{x}-0.0275$ & 0.998 \\
$\Delta$-stigmasterol & $\mathrm{y}=0.0594 \mathrm{x}-0.0615$ & 0.997 \\
\hline
\end{tabular}

Oil samples were spiked with six standard phytosterols at low, middle, and high concentrations, and repeatability and recovery tests $(n=6)$ were performed to verify the precision and accuracy of the method. The recoveries and repeatabilities of six phytosterols were shown in Table 3. 
Table 3. Within-day precisions and recoveries of selected phytosterols

\begin{tabular}{|c|c|c|c|}
\hline Compounds & $\begin{array}{l}\text { Spiking amount } \\
(\mathrm{mg} / \mathbf{1 0 0 g})\end{array}$ & $\begin{array}{c}\text { Within-day precision } \\
(R S D, \%)\end{array}$ & Mean Recovery (\%) \\
\hline \multirow[t]{3}{*}{ Campesterol } & 15 & 4.0 & 98.1 \\
\hline & 30 & 3.2 & 100 \\
\hline & 60 & 4.1 & 100 \\
\hline \multirow[t]{3}{*}{ Stigmasterol } & 15 & 4.2 & 99.3 \\
\hline & 30 & 3.0 & 96.4 \\
\hline & 60 & 2.2 & 93.5 \\
\hline \multirow[t]{3}{*}{ Beta sitosterol } & 15 & 2.6 & 99.6 \\
\hline & 30 & 2.9 & 101 \\
\hline & 60 & 2.1 & 95.7 \\
\hline \multirow[t]{3}{*}{$\Delta 5$-avenasterol } & 15 & 3.3 & 96.2 \\
\hline & 30 & 2.6 & 98.5 \\
\hline & 60 & 3.8 & 99.4 \\
\hline \multirow[t]{3}{*}{$\Delta 7$-avenasterol } & 15 & 3.9 & 96.8 \\
\hline & 30 & 3.5 & 100 \\
\hline & 60 & 3.7 & 100 \\
\hline \multirow[t]{3}{*}{$\Delta 7$-stigmaterol } & 15 & 4.2 & 97.8 \\
\hline & 30 & 3.4 & 99.4 \\
\hline & 60 & 3.6 & 100 \\
\hline
\end{tabular}

The relative standard deviation (RSD) of the repeatability for determination of the selected phytosterols ranges from 2.1 to $4.2 \%$, which indicates that the precision of the analytical method is acceptable over the three concentration levels. The mean recoveries range from 93.5 to $101 \%$. The relative standard deviation and recovery are in the allowed range AOAC [3].

\subsection{Application to real vegetable oil samples}

In this study, five types of vegetable oil were analyzed using the developed method. The contents of six phytosterols were shown in Table 4.

Table 4. Contents of six phytosterols in vegetable oils

\begin{tabular}{|c|c|c|c|c|c|}
\hline Oil type & $\begin{array}{c}\text { Soybean oil } \\
(m g / 100 g)\end{array}$ & $\begin{array}{l}\text { Sunflower oil } \\
(\mathrm{mg} / \mathrm{l00g})\end{array}$ & $\begin{array}{l}\text { Rice bran oil } \\
\quad(m g / 100 g)\end{array}$ & $\begin{array}{c}\text { Palm oil } \\
(\mathrm{mg} / \mathrm{l00g})\end{array}$ & $\begin{array}{l}\text { Rapeseed oil } \\
\text { (mg/100g) }\end{array}$ \\
\hline Campesterol & 47.5 & 42.2 & 130 & 27.1 & 33.0 \\
\hline Stigmasterol & 54.1 & 82.7 & 6.65 & 96.1 & 33.3 \\
\hline Beta-sitosterol & 825 & 850 & 1,064 & 218 & 992 \\
\hline$\Delta 5$-avenasterol & 67.9 & 45.4 & 25.2 & 107 & 28.1 \\
\hline$\Delta 7$-avenasterol & 143 & 136 & 189 & 40.7 & 27.7 \\
\hline$\Delta 7$-stigmaterol & 127 & 135 & 22.9 & 51.6 & 76.3 \\
\hline Total & 1,264 & 1,291 & 1,438 & 540 & 1,190 \\
\hline
\end{tabular}


Contents of beta-sitosterol in the oil samples are highest among all the analytes. Betasitosterol in soybean oil, sunflower oil, rice oil, and canola oil accounts for over $50 \%$ of the total phytosterol content (six types), the results are in line with other previous studies $[1,8]$, the comparation results are shown in Table 5. The total phytosterol content was lowest in palm oils, highest in rice oil, and similar in the other tested oils. The concentrations of each phytosterol in palm oil are far different.

Table 5. Proportions of beta-sitosterol in total phytosterols fraction in some studies

\begin{tabular}{ccccccccc}
\hline \multirow{2}{*}{ Oil type } & \multicolumn{2}{c}{ Soybean oil } & \multicolumn{3}{c}{ Sunflower oil } & \multicolumn{2}{c}{ Rapeseed oil } \\
\hline \multirow{2}{*}{ Lab } & Our study & {$[1]$} & Our study & {$[1]$} & {$[8]$} & Our study & {$[8]$} \\
\cline { 2 - 8 } & 65.2 & 56.7 & 65.8 & 69.6 & 78.7 & 83.3 & 81.2 \\
\hline
\end{tabular}

\section{CONCLUSION}

The gas chromatography-mass spectrometry method was validated for the simultaneous analysis of six phytosterols in vegetable oils. The method has a high specificity and accuracy, meeting the requirements of AOAC. The method has been used for the determination of phytosterols in five kinds of edible oils on the local market. These results can be used for further studies for the determination of the composition of other oils and substances of the phytosterol group, contributing to a better understanding of the importance of phytosterols for human health.

\section{ACKNOWLEDGMENT}

The authors wish to thank the funding and facilities of the National Institute for Food Control for the implementation of this study.

\section{REFERENCES}

[1]. M. J. Lerma-Garcia, E. F. Simo-Alfonso, A. Mendez, J. L. Liberia and Jose Manuel HerreroMarinez, "Fast separation and determination of sterols in vegetable oil by ultraperformance liquid chromatography with atmospheric pressure chemical ionization mass spectrometry detection", Journal of Agriculture and Food Chemistry, vol. 58, pp. 2771-2776, 2010.

[2]. I. Borkovcava, E. Janouskova, M. Drackova, B. Janstove and L. Vorlova, "Determination of sterols in dairy products and vegetable fats by HPLC and GC methods", Czech Journal of Food Science, vol. 27, 2008.

[3]. AOAC Official Methods of Analysis, Appendix F: Guidelines for standard method performance requirements. 2012.

[4]. AOAC Official methods 2007.03, "Campesterol, Stigmaterol, and beta-sitosterol in saw palmetto raw materials and dietary supplements", 2007.

[5]. Y-Z. Chen, S-Y. Kao, H-C. Jian, Y. Yu, J-Y. Li, W-H Wang and C-W. Tsai, "Determination of cholesterol and four phytosterols in food without derivatization by gas chromatographytandem mass spectrometry", Journal of Food and Drug Analysis, vol 23, no. 4, pp. 1-9, 2015. 
[6]. R. Yang, L. Xue, L. Zhang, X. Wang, X. Qi, J. Jiang, L. Yu, X. Wang, W. Zhang, Q. Zhang and P. Li, " Phytosterol contents of edible oils and their contributions to extimated phytosterol intake in the Chinese diet", Foods, vol. 8, no. 334, pp. 2-12, 2019.

[7]. S. L. Abidi, "Chromatographic analysis of plant sterols in foods and vegetable oils", Journal of Chromatography A, vo. 935, pp. 173-201, 2001.

[8]. B. Xu, S. You, L. Zhou, H. Kang, D. Luo, H. Ma and S. Han, "Simultaneous determination of free phytosterols and tocopherols in vegetable oils by an improved SPE-GC-FID method", Food Ananlytical Methods, vol. 13, no. 2, pp. 1-12, 2020.

[9]. N. Qi, Y. Liu, L. Liao, X. Gong and C. Yang, "A new method for determination of campesterol, stigmaterol and $\beta$-sitosterol in edible oils by suprcritical fluid chromatography", Journal of Food and Nutrition Reseach, vol. 58, no. 4, pp. 363-369, 2019.

\title{
Xác định Phytosterols trong dầu thực vật bằng sắc ký khí khối phổ GC-MS
}

\author{
Đặng Thu Hiền, Mai Thị Ngọc Anh, Nguyễn Thị Hồng Ngọc \\ Viện Kiêm nghiệm an toàn vệ sinh thực phẩm quốc gia, Hà Nội, Việt Nam
}

\section{Tóm tắt}

Trong nghiên cứu này, phương pháp sắc ký khí khối phổ kết hợp với việc dẫn xuất hóa đã được thẩm định và áp dụng để phân tích đồng thời sáu chất nhóm phytosterol trong dầu thực vật . Mẫu được thủy phân trong tủ ấm $70^{\circ} \mathrm{C}$ trong 60 phút, rôi được chiết với toluen. Các chất nhóm phytosterol được dẫn xuất với trimethysilyl ether trước khi phân tích trên hệ thống sắc ký khí khối phổ. Giới hạn phát hiện và giới hạn định lượng của phương pháp lần lượt là 5 và 15 mg/kg. Độ thu hồi của cả sáu chất nhóm phytosterol trong khoảng từ 93,5 đến 101\%.

Tư khóa: GC-MS, phytosterols, dầu thực vật. 